\title{
A Study On The Effect Of Feng Shui Interest On Feng Shui Recognition Of Location And Management Performance: With Small Businesses As Subject
}

\author{
Park Yeon-Su ${ }^{1 *}$ \\ ${ }^{1}$ Department of Financial Accounting/Real Estate, Dong-Eui University, Korea
}

Article History: Received:11 January 2021; Accepted: 27 February 2021; Published online: 5 April 2021

\begin{abstract}
The purpose of this study is to derive the main factors of Feng Shui site recognition and the effect of the factors on the Management Performance of small business through the previous studies in order to investigate the relationship between Feng Shui interest and management performance for the sake of development of small businesses. In addition, the research is directed to the mediating effect of Feng Shui site recognition and adjusted mediating effect of entrepreneurship in the relationship between Feng Shui interest and management performance.
\end{abstract}

First, the verification of the hypothesis, 'Feng Shui interest will have a positive influence on the Feng Shui site recognition', showed that Feng Shui interest had a positive influence on all the space placement, space shape, junction space, and topography.

Second, the verification of the hypothesis, 'Feng Shui site recognition will have a positive effect on management performance', showed that Feng Shui site recognition had a positive effect on characteristics of Feng Shui site recognition such as space placement, junction space and topography, but not on space shape.

Third, the verification of the hypothesis, 'Feng Shui site recognition will mediate the influence of Feng Shui interest has on management performance', showed that Feng Shui site recognition had a positive effect on characteristics of Feng Shui site recognition such as space placement, junction space and topography, but statistically not significant on space shape.

Fourth, the verification of the hypothesis, 'innovation will control the mediating effect of Feng Shui site recognition in the path that Feng Shui interest affects management performance through Feng Shui site recognition', showed that innovation controlled the mediating effect.

It is necessary not to confine the subject of research to small businesses, but to extend it to medium- or largesized companies. In addition, it is necessary to research the impact of Feng Shui site recognition not only on the management field but also on other fields.

Keywords - Feng Shui interest, Feng Shui site recognition, Management performance, Innovation, Controlled mediating effect

\section{INTRODUCTION}

Until the 1990s, Korean companies have used exhibitions only as a means of promoting sales and raising corporate image. The main activity has been to grasp consumer needs and information of new companies and competitors, to secure new markets and potential customers, and to introduce new products. In addition, the characteristics of one-sided information transmission and rapid changes in the consumption environment of radio, $\mathrm{TV}$, and newspapers in the past have difficulty in forming a close relationship between companies and consumers. Focusing on the product promotion function, which is a unique role of the corporate publicity exhibition hall, is admitted to be retrograde.

Today's corporate publicity exhibition halls not only have their own product promotion functions, but also play the new media of communication through communication activities between companies and consumers, and provide information of their own companies, convenience facilities, and complex cultural spaces. However, the

Received:

Reviewed:

Accepted:

* Corresponding Author 
recognition and research on the corporate publicity exhibition hall is insufficient, and the empirical research on the effect is very lacking.

In this regard, this study tries to examine the effects of exhibition experience on satisfaction, brand assets and consumer behavioral intention in order to suggest the necessity and direction of development of the corporate publicity exhibition hall. In addition, it will identify the advantages and disadvantages of the exhibition experience at the current corporate publicity exhibition hall, and suggest improvement plans and future directions. It will find a way to develop it into a space that can promote intimacy between companies and consumers, and satisfy various demands of consumers through exchange of information and communication, and that can provide cultural services through cutting-edge exhibition and display techniques to consumers and potential customers, and form a local culture that contributes to the region.

\section{Theoretical Background}

\subsection{Feng Shui interest}

Feng Shui Geography is an Oriental geography and an empirical scientific study[1], which seek a place for men, animals and plants[Human] to live more healthily and comfortably in the nature by studying the circulation principle of wind and water[Sky], the process of land formation, and the geological conditions based on the YinYang and Five Elements Theory. It is a practical study[2] with the method to grasp the various influences of natural factors such as geology, sunshine, weather, wind direction, waterway, landscape, etc. on living thing, to cover their superiority, and to select only the best among them and use them in life.

Like this, Feng Shui is a scientific study that utilizes natural phenomena comfortably in human life to pursue human development and happiness, and in particular, judges the fortune based on the change of land, and builds at east inhabited buildings or collects the remains of ancestors pursuing health, wealth and happiness of residents and offspring through the energy of the earth, and maximizes at most the rationality, preservation and efficiency of land use, and promotes the safety and convenience of human life by developing a balanced environment in harmony with nature.

Feng Shui is basically looking for a way[3] for humans to live together with the nature without getting harm by discriminating between good and bad lands through observing basically the natural phenomena, that is, the movement of wind and water. The purpose of Feng Shui[4] is to enhance the adaptability of human beings to the residential environment by interpreting and discriminating the change of the earth according to the five elements and Feng Shui theory under the assumption that everything in the universe is constantly changing. On the other hand, another purpose of Feng Shui is to set the ancestor's grave at the place with the lively and vigorous energy of earth so that the soul can rest in peace and invoke happy life for the offspring. Therefore, Feng Shui interest can be said to be the degree of application of attitudes and recognition to achieve the purpose of Feng Shui described above.

\subsection{Feng Shui site recognition}

This study attempted to organize the sub-factors on Feng Shui site recognition into four categories such as space placement, space shape, junction space, and topography, and study the effect of those sub-factors on management performance. As for space placement, the condition of front-low-rear-high and the principle of entrance-narrowinside-large means that the gate and entrance located in front of the building should be narrow and the yard or the interior should be wide[5]. As for the space shape, the mutual harmony and synthesis between two energies flowing in the three-dimensional space and the planar space should be formed in the inseparable synchronous relationship, and the ratio of the three-dimensional space and the planar space should be under the condition of $0.577 \sim 0.866: 1$ or $1: 0.577 \sim 0.866[6]$.

In case of junction space, the exterior of the building in junction should be a square and upright with no irregularities to be auspicious. When building a structure on the ground adjacent to the road, there are methods of front, middle and rear layouts depends on how far it is from the road[7]. The purpose of topography is the same as the grave Feng Shui that looks for sites where vitality remains, since house site or residential Feng Shui aim at looking for Jinhyeol where there is full of vitality that flows along a certain path in the ground. However, the difference between the grave and the house is on the size, so when discussing the topographical Feng Shui, the logical structure of Yong, Hyeol, Sa, and Su should be applied[8].

\subsection{Feng Shui analysis of commercial area}

Myeongdang is the place where the good spirit gathers in traditional Feng Shui. Myeongdang is, in a word, a land with a lot of good energy. A good energy is a spirit that gives health to people, makes them feel comfortable, 
and motivates them to live. A land with especially a lot of good energy was called Hyeol[9]. The size of Hyeol that occupies the most important place in Myeongdang is generally within a radius of 1 to 2 meters, and about 10 meters at most, so it is very important to find the correct Hyeol in the case of grave. However, in corporate Feng Shui, we must approach the concept of a larger area than the Myeongdang and Hyeol that fall into the small area where the energy gathers.

The whole universe is full of energy, and the word feeling, Ki-bun is the combination of energy, $\mathrm{Ki}$ and to divide, Bun, in the sense that humans share the energy of the universe. Therefore, all the human beings who have feeling come together at the place where good energy gathers to form a city, to make a market, to build a structure, and to form a business district. Therefore, the area that attracts humans and place where good spirits gather to improve human life were called Myeongji, referring to a bigger region than Myeongdang, and out of Myeongji, the place where a lot of people and energy gather was called So.

\subsection{Management Performance}

Management performance is defined in various ways including the ability to achieve organization's goal and acquire the resources needed by the organization, the ability to adapt to changing environments to survive, the ability to develop the human resources and organize to meet the needs of members, and corporate productivity or profitability[10].

The management performance of a company is the result of effective and efficient management of the human and physical resources of the company. The management performance of a company can be viewed as the results that each business unit, function, task, group, and individual that make up the company achieve to realize the goal of the company, that is, the sum of the performance of the responsibility unit. A company has a variety of goals that an organization must achieve over a fixed period of time, and the achievement of the organization's goals can be expressed as performance.

\subsection{Innovation}

Innovation is one of the important components in the study of entrepreneurship. Miller (1983) argued for three dimensions of entrepreneurship: innovation, progressiveness and risk-taking[11]. Stevenson \& Jallio (1990) also categorized into innovative risk-taking to create new value and activities to redistribute or recombine resources progressively[12], and afterward more various opinions were proposed based on it. Dean et. al.(1993) expanded the factors of Miller(1983) and added the concept of competitive and aggressiveness[13], and Lumpkin \& Dess(1996) also argued that competitive positiveness, independence and autonomy were important components of entrepreneurship[14].

\section{Research Design}

In order to empirically verify the flow of research, this study established the following research model to achieve the purpose of research based on the models related to Feng Shui interest, Feng Shui site recognition, management performance, and entrepreneurship suggested in previous studies.

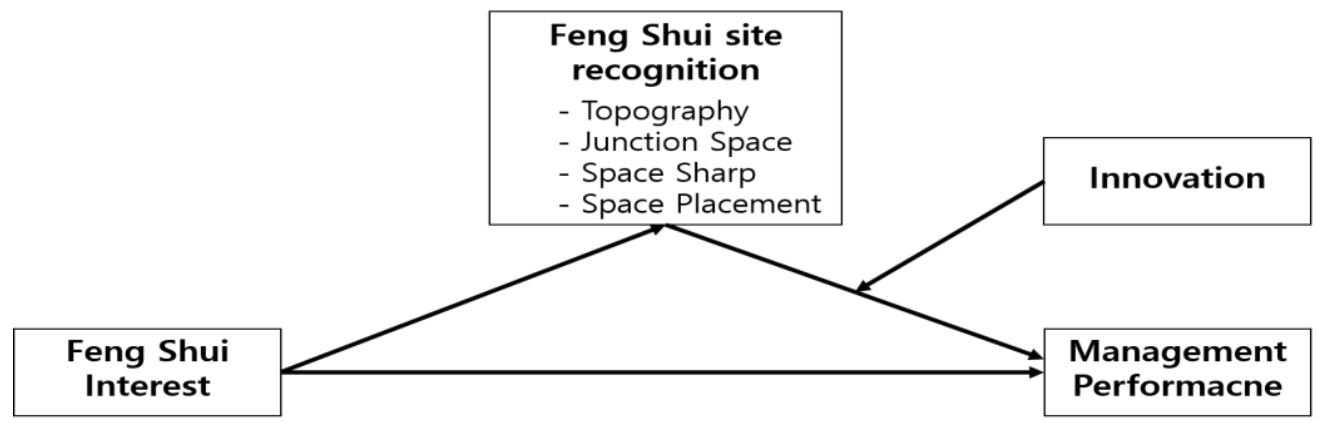

Fig. 1 Research Model

In addition, the causal hypothesis method was used to grasp the interaction relationship between Feng Shui interest as an independent variable and management performance as a dependent variable, and four hypotheses were set as follows to verify the research model. 
$<$ Hypothesis 1> Feng Shui Interest will have a positive effect on Feng Shui site recognition.

$<$ Hypothesis 2> Feng Shui site recognition will have a positive effect on management performance.

$<$ Hypothesis 3> Feng Shui site recognition will mediate the effect of Feng Shui interest on management performance.

$<$ Hypothesis 4> Innovation will control the mediating effect of Feng Shui site recognition in the path that Feng Shui interest affects management performance through Feng Shui site recognition.

\section{Empirical Analysis}

\subsection{Relationship between Feng Shui interest and Feng Shui site recognition}

The results of hypothesis 1, 'Feng Shui interest will have a positive effect on Feng Shui site recognition', are shown in $\langle$ Table 1>. Feng Shui interest had a significant effect on all the Feng Shui site factors, as the regression coefficient of space placement is $\mathrm{B}=.643(\mathrm{t}=8.434, \mathrm{p}=.00)$, that of space shape is $\mathrm{B}=.6142(\mathrm{t}=7.1978, \mathrm{p}=.00)$, and that of junction space is $\mathrm{B}=.4765(\mathrm{t}=6.2791, \mathrm{p}=.00)$, and that of topography is $\mathrm{B}=.5084(\mathrm{t}=8.2217, \mathrm{p}=.000)$.

Table 1. Regression Analysis of Feng Shui Interests and Feng Shui Site Recognition

\begin{tabular}{|c|c|c|c|c|c|c|c|}
\hline Preceding Varic & Result Variabli & Coet & $\mathrm{SI}$ & $\mathrm{t}$ & 1 & & $\mathrm{~F}$ \\
\hline \multirow{8}{*}{ Feng Shui Inte } & Constant & 1.09 & .291 & 3.75 & .00 & \multirow{2}{*}{.2} & \multirow{2}{*}{71.12} \\
\hline & Space Placeme & .643 & .07 & 8.43 & .00 & & \\
\hline & Constant & 1.51 & .32 & 4.65 & .00 & \multirow{2}{*}{.2} & \multirow{2}{*}{51.80} \\
\hline & Space Shape & .614 & .08 & 7.19 & .00 & & \\
\hline & Constant & $1.79 x$ & .28 & 6.20 & .00 & \multirow{2}{*}{.1} & \multirow{2}{*}{39.42} \\
\hline & Junction Spac & .476 & .07 & 6.27 & .00 & & \\
\hline & Constant & $1.87 €$ & .23 & 7.95 & .00 & \multirow{2}{*}{.2} & \multirow{2}{*}{67.59} \\
\hline & Topography & .508 & .06 & 8.22 & .00 & & \\
\hline
\end{tabular}

\subsection{Relationship between Feng Shui site recognition and management performance}

The results of hypothesis 1, 'Feng Shui site recognition will have a positive effect on management performance', are shown in <Table 2>. Space placement $(\mathrm{B}=.1726, \mathrm{t}=2.764, \mathrm{p}=.063)$, junction $\operatorname{space}(\mathrm{B}=.2072, \mathrm{t}=3.4982, \mathrm{p}=.006)$ and topography $(B=.4379, t=6.1319, p=.00)$ were found out to be significant, while space shape $(B=.0593, t=1.1074$, $\mathrm{p}=.2696$ ) was statistically not significant.

Table 2. Regression Analysis of Feng Shui Site Recognition and Management Performance

\begin{tabular}{rrrrrrrr}
\hline Preceding Varial & Result Variak & coeff. & $\vdots$ & $\mathrm{t}$ & $\mathrm{l}$ & $\mathrm{J}$ & $\mathrm{F}$ \\
\hline Constant & & .0888 & .2 & $.35 t$ & .7 & & \\
Feng Shui Inter & & .0367 & .0 & .52 & .5 & & \\
Space Placeme & & .1726 & .0 & 2.76 & .0 & & \\
Space Shape & Management Perf & .0593 & .0 & 1.10 & $.2 t$ & .5 & 43.12 \\
Junction Spac & & .2072 & .0 & 3.49 & .0 & & \\
Topography & .4379 & .0 & 6.13 & .0 & & \\
\hline
\end{tabular}

4.3. The mediating effect of Feng Shui site recognition in the relationship between Feng Shui interest and management performance 
The bootstrapping method was used to verify the significance of the mediating effect more accurately. In case of verifying the mediating effect using bootstrapping, it can be said that the mediating effect is significant at .05 level unless the $95 \%$ confidence interval for the mediating effect estimate contains zero.

Table 3. Analysis of mediating effect of Feng Shui site recognition

\begin{tabular}{|c|c|c|c|c|c|c|c|}
\hline Preceding Variab & Result Variak & Coes & $\mathrm{S}$ & $\mathrm{t}$ & ] & ] & $\mathrm{F}$ \\
\hline \multirow{8}{*}{ Feng Shui Intere- } & Constant & 1.091 & .29 & 3.75 & .00 & \multirow{2}{*}{.2} & \multirow{2}{*}{71.12} \\
\hline & Space Placen & .643 & .07 & 8.43 & .00 & & \\
\hline & Constant & 1.51 & .32 & 4.65 & .00 & \multirow{2}{*}{.2} & \multirow{2}{*}{51.80} \\
\hline & Space Shap & .614 & .08 & 7.19 & .06 & & \\
\hline & Constant & 1.79 & .28 & 6.20 & .06 & \multirow{2}{*}{$.1^{\prime}$} & \multirow{2}{*}{39.42} \\
\hline & Junction Spa & .476 & .07 & 6.27 & .06 & & \\
\hline & Constant & 1.871 & .23 & 7.95 & .06 & \multirow{2}{*}{.2} & \multirow{2}{*}{$67.59 t$} \\
\hline & Topograph & .508 & .06 & 8.22 & .00 & & \\
\hline Constant & \multirow{6}{*}{ Management Perf } & .088 & .24 & $.35 t$ & $.7 \%$ & \multirow{6}{*}{.5} & \multirow{6}{*}{43.12} \\
\hline Feng Shui Intere & & .036 & .06 & .52 & .5 & & \\
\hline Space Placemer & & .172 & .06 & 2.76 & .00 & & \\
\hline Space Shape & & .059 & .05 & 1.10 & $.2 t$ & & \\
\hline Junction Space & & .207 & .05 & 3.49 & .06 & & \\
\hline Topography & & .437 & .07 & 6.13 & .00 & & \\
\hline
\end{tabular}

The indirect effect of space placement was significant as $95 \% \mathrm{BC}$ bootstrap confidence interval of the results was $[0.0272,0.2083]$, while the indirect effect of space shape was not significant as $95 \%$ BC bootstrap confidence interval of the results was $[-0.0302,0.1080]$.

The indirect effect of junction space was significant as 95\% BC bootstrap confidence interval of the results was $[0.0446,0.1648]$, and the indirect effect of space shape was significant as $95 \%$ BC bootstrap confidence interval of the results was [0.1421, 0.3158].

Therefore, space placement, junction space and topography were found out to have a mediating effect on the relationship between Feng Shui interest and management performance, while space shape does not have.

Table 4. Bootstrap verification for analysis of mediating effects of Feng Shui site recognition

\begin{tabular}{|c|c|c|c|c|c|}
\hline \multicolumn{2}{|c|}{ Variables } & Coeff. & SE or Boots & LLC. & ULCI \\
\hline \multicolumn{2}{|l|}{ Direct Effe } & .0367 & .0695 & -.100 & .1738 \\
\hline \multirow{4}{*}{ Indirect Eff } & Space Placemes & .1110 & .0449 & $.027_{2}$ & .2083 \\
\hline & Space Shape & .0364 & .0353 & -.030 & .1080 \\
\hline & Junction Space & .0987 & .0305 & $.044 t$ & .1648 \\
\hline & Topography & .2227 & .0438 & .1421 & .3158 \\
\hline
\end{tabular}

\subsection{The adjusted mediation effect of innovation in the relationship between Feng Shui interest, Feng Shui site recognition and management performance}

The analysis of adjusted mediation effect of innovation of entrepreneurship, showed that the higher the innovation of entrepreneurship is, the more the indirect effect of the adjusted mediating effect increases as shown in [Table 5] and [Table 6] $(-1 \mathrm{SD}=.1578$, mean $=.2406,+1 \mathrm{SD}=.3233)$. In addition, all three groups of innovation 
are statistically significant as they do not contain zero between the lowest limit and highest limit value of indirect effect.

Table 5. Analysis of mediating effect controlled by innovation

\begin{tabular}{|c|c|c|c|c|c|c|c|}
\hline Preceding Variabl & Result Variables & Co & 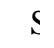 & & & & $\mathrm{F}$ \\
\hline \multirow{6}{*}{ Feng Shui Interes } & Constant & 1.0 & $.2 !$ & 3.7 & .0 & \multirow{2}{*}{.2} & \multirow{2}{*}{ 71.12 } \\
\hline & Space Placement & 6 & $.0^{\prime}$ & 8.4 & .0 & & \\
\hline & Constant & 1.7 & $.2 i$ & 6.2 & .0 & \multirow{2}{*}{.1} & \multirow{2}{*}{$39.42^{\circ}$} \\
\hline & Junction Space & 4 & .0 & 6.2 & .0 & & \\
\hline & Constant & 1.8 & .2 & 7.9 & .0 & \multirow{2}{*}{.2} & \multirow{2}{*}{$67.59 t$} \\
\hline & Topography & .5( & .01 & 8.2 & .0 & & \\
\hline Constant & \multirow{6}{*}{ Constant } & 1.3 & 1.C & 1.2 & .1 & \multirow{9}{*}{.5} & \multirow{9}{*}{$28.69 t$} \\
\hline Feng Shui Interes & & .0 & $.0^{\prime}$ & 1.3 & .1 & & \\
\hline Space Placemen & & $.0]$ & .21 & $.0 x$ & .9 & & \\
\hline Junction Space & & .64 & .21 & 2.4 & .0 & & \\
\hline Topography & & -.0 & .31 & -.2 & .7 & & \\
\hline Innovation & & -.4 & .3 & $-1 .<$ & .1 & & \\
\hline Space Placement*Innc & & $.0 \leq$ & .0 & .6 & .5 & & \\
\hline Junction Space *Inno' & & -.1 & .0 & $-1 . i$ & .0 & & \\
\hline Topography*Innove & & $.1 \xi$ & .0 & 1.8 & .0 & & \\
\hline
\end{tabular}

Table 6. Bootstrap verification of significance of mediating effect controlled by innovation

\begin{tabular}{|c|c|c|c|c|c|}
\hline \multicolumn{2}{|c|}{ Variables } & \multirow{2}{*}{$\begin{array}{l}\text { Coeff. } \\
.0947\end{array}$} & \multirow{2}{*}{$\begin{array}{r}\text { SE or Boot } \\
.0723\end{array}$} & \multirow{2}{*}{$\begin{array}{l}\text { LLC } \\
-.048\end{array}$} & \multirow{2}{*}{$\frac{\mathrm{ULC}}{.237}$} \\
\hline Direct Effer & & & & & \\
\hline \multirow{3}{*}{ Indirect Eff $\epsilon$} & Space Placement & .0334 & .0501 & -.064 & .131 \\
\hline & Junction Space & -.0655 & .0341 & -.132 & .004 \\
\hline & Topography & .0923 & .0544 & -.016 & .196 \\
\hline
\end{tabular}

\section{Conclusion}

This study derived key factors of Feng Shui site recognition for the development of small business and selfemployed business in Busan, Gyeongnam, and Gyeongbuk, and examined the effects of these factors on the management performance of small business owners. In addition, the research tried to present basic data necessary in promoting small business owners by examining comprehensively through empirical research which adjusting function will the entrepreneurship brings about in the relationship between Feng Shui site recognition and management performance, and the mediating role of Feng Shui site recognition in the relationship between Feng Shui interest and management performance.

The results obtained from the analysis can be summarized as follows.

The weaker the trend of Feng Shui interest, the lower the Feng Shui site recognition (space placement, space shape, junction space and topography), and the lower Feng Shui site recognition means that the lower management performance is predicted. The stronger the trend of Feng Shui interest, the higher the Feng Shui site recognition, and the higher Feng Shui site recognition means that the lower management performance is predicted. In addition, the adjusted mediating effect shows statistically significant, as it is observed that the higher the innovation, the more the management performance is amplified, while the lower the innovation, the more the positive influence of management performance is decreased. 
These results imply that the effects, which appear in the path of Feng Shui interest, Feng Shui site recognition (space placement, junction space and topography) and management performance, can be significantly adjusted according to the innovation of entrepreneurship. In particular, it suggests that the mediating effect of Feng Shui site recognition in between the Feng Shui interest and management performance can be more greatly experienced when the innovation is high.

The implications of this study can be summarized into two main categories as follows. First of all, considering the mediation path of Feng Shui Interest - Feng Shui site recognition - management performance was significant, the factors of Feng Shui site recognition such as topography, junction space, space shape, etc. in the process of analysis of site commercial rights need to be considered as a success factor of small capital business activities. These results, however, indicate that people with high Feng Shui interest will reflect Feng Shui interests in the process of creating a business space, and the Feng Shui site recognition of business space gives rise to expectations and beliefs about Feng Shui's blessing, operating the noble man mechanism based on Feng Shui. The other is that innovation works as a driving factor in management performance recognition in case that the topography, which might be the most important factor of blessing in traditional discourse, is considered good. This does not indicate that Feng Shui is merely good, but that human subjective efforts and roles are one of the key factors of business performance.

Existing previous studies have been conducted mainly through case studies, but this study could provide specific data to small business owners through empirical analysis. The significance of this study is in that it can provide the basis for applying Feng Shui site recognition to small business owners who are preparing or starting a business in the future.

It is necessary not to confine the subject of research to small businesses, but to extend it to medium- or largesized companies. In addition, it is necessary to research the impact of Feng Shui site recognition not only on the management field but also on other fields.

\section{ACKNOWLEDGMENTS}

This study was written by revising and supplementing this researcher's doctoral dissertation.

\section{REFERENCES}

[1] Song, Seung-Ho, "A Geomantic Study on Location and Space Composition of Hyang-gyo in Ulsan Area", M.S thesis Yeong-Nam University, 2019, p.8.

[2] Kim, Kyung-Hee, "A Corelation Analysis betwen Feng Shui and Oficialy Asesed Land Price: Centering on the Single-Family Houses in Seongbuk-dong", Ph.D Seo-Kyeong University, 2019, p.10.

[3] Seo, Kyung-Im, "A Study on the position of the Yeongguk Temple of Mt. Cheontae by the Feng-Shui", M.S thesis Yeong-Nam University, 2018, pp.6-7.

[4] Hong, Seong-Seo, "A Study on DonggiGameung in Theory of Topographic Divination: Focused on cases of outbreak of disease", M.S thesis Yeong-Nam University, 2009, p.9.

[5] An, Hae-Woo, "The research for the effects of the geomantic system of topography used in choosing auspicious sites for houses", M.S thesis Jung-Ang University, 2008, p.46.

[6] Park. Yeon-Su, "A Study of the Identity of House Shape and House Destiny when the Feng-shui Habitation has an effect on Family Circumstances", M.S thesis Dong-Guk University, 2012, p.43.

[7] Sim. Jae-Yeal, "A Study on the Effect of Feng Shui on the Determinant of Location Selection", Ph.D In-Cheon University, 2010, p.106.

[8] Park, Mu-Heoml, "The study of correlations with the principle of topography and anatomy in viewpoint of oriental medicine", Ph.D Young-San University, 2011, p.95.

[9] Park, Si-Ik, "A Study on the background and origin of Feng-shui theory", Korea University, Vol. 5 (1987):184189. 
[10] Jung, So-Jin, "A study on the influence of franchisor's support on relation bonding between franchisor and franchise and long-term relationship", M.S thesis Dong-A University, 2006, p.38.

[11] Miller, D. \& Friesen, P. H., "The correlates of entrepreneurship in three types of firms", Management science, Vol.29 No.7 (1983):770-791.

[12] Stevenson, H. H. \& Jarillo, J. C., "A paradigm of entrepreneurship: entrepreneurial management", Strategic management journal, Vol.11 No.5 (1993):17-27.

[13] Stevenson, H. H. \& Jarillo, J. C., "Corporate Entrepreneurship and Competitive Aggressiveness: A Comparison of US Firms Operating in Eastern Europe and the Commonwealth of Independent States with US Firms in other High Risk Environments", Advances in International Comparative Management, Vol.8, (1993):31-54.

[14] Lumpkin, G. T. \& Dess, G. G., "Clarifying the entrepreneurial orientation construct and linking it to performance", Academy of management Review, Vol.21 No.1 (1996):135-172.

[15] Yeon-Su, Park, "A Study on the Relationship between Feng Shui Interest and Management Performance," International Journal of IT-based Management for Smart Business, vol.7 no.1, Jul, (2020), Global Vision Press, pp.15-22,10.21742/IJITMSB.2020.7.1.03

[16] Soo-Yong Park, Dong-Hyung Lee. "The Effects of the Compassionate Rationalism Leadership of CEO on Management Performance in Small and Medium-sized Enterprises". Asia-pacific Journal of Law, Politics and Administration. Vol. 2. No. 2. Oct. 2018.GVPress. pp:71-76.http://dx.doi.org/10.21742/AJLPA.2018.2.2.10

[17] Xiaoqing Feng, Yanan Cao and Yangyang Li. "Medical Service Platform and Internet+ Medicine Innovation Construction". International Journal of Advanced Nursing Education and Research. Vol. 4. No. 1. Apr. 2019.GVPress. pp:25-30.http://dx.doi.org/10.21742/IJANER.2019.4.1.04

[18] Jae Eon Yu. “Understanding Social Innovation from Systemic Perspectives”. International Journal of Business Policy and Strategy Management. Vol. 4. No. 2. Nov. 2017.GVPress. pp:3338.http://dx.doi.org/10.21742/IJBPSM.2017.4.2.05

[19] Jaesik Lee, Chulung Lee, Jaejin Kim, Seiho Kim, Hyeonu Im. “A Study on the Effective Innovation Financing on Technology Innovation Competency and Business Performance of SMEs". International Journal of ITbased Business Strategy and Management. Vol. 2. No. 1. Dec. 2016.GVPress. pp:2532.http://dx.doi.org/10.21742/IJBSM.2016.2.1.04

[20] Byeouk-Gyu Lee, Myung-Bae Yeom, Eul-Hyun Sung. "Characteristics of German Innovation System in the Edge of the Fourth Industrial Revolution". International Journal of IT-based Business Strategy and Management. Vol. 4. No. 1. Jul. 2018.GVPress. pp:19-22.http://dx.doi.org/10.21742/IJBSM.2018.4.1.04

[21] Lei Li. "Innovation Mode of Application-oriented Undergraduate Education Management in the Era of Big Data". International Journal of Computer Science and Information Technology for Education. Vol. 3. No. 2. Dec. 2018.GVPress. pp:17-24.http://dx.doi.org/10.21742/IJCSITE.2018.3.2.03

[22] Dr. Keshab Nandy, “The Performance Management System - An Indian Perspective”, International Journal of Human Resource Management and Research (IJHRMR), Vol. 9, Issue 4, pp , 1-8

[23] A. P Achar \& Deepa Nayak, "An Evaluation of Performance Management System in Health Care Organization- A Case Study", International Journal of Human Resource Management and Research (IJHRMR), Vol. 4, Issue 3, pp, 9-18

[24] Rheinanda Raissa Dasril, "Designing of Key Performance Indicators for Assessing Yes Cake \& Bakery Employee's Performance", International Journal of Human Resource Management and Research (IJHRMR), Vol. 8, Issue 5, pp, 43-56

[25] vIsaac Zeb-Obipi, "Corporate Productivity Performance: A Harmonist Framework", International Journal of Business and General Management (IJBGM), Vol. 4, Issue 1, pp, 19-28

[26] Ayman. A. S. Almusaddar, Sara Ravan Ramzan \& Valliappan Raju, "The Influence of Knowledge, Satisfaction, and Motivation on Employee Performance through Competence", International Journal of Business and General Management (IJBGM), Vol. 7, Issue 5, pp; 21-40 
[27] Preeti Garg \& Maanvi Panchal, "Managing Workforce Diversity to Improve Business Performance - A Study on Mncs in Delhi Region", BEST: International Journal of Management, Information Technology and Engineering (BEST: IJMITE), Vol. 4, Issue 10, pp, 29-34.2 